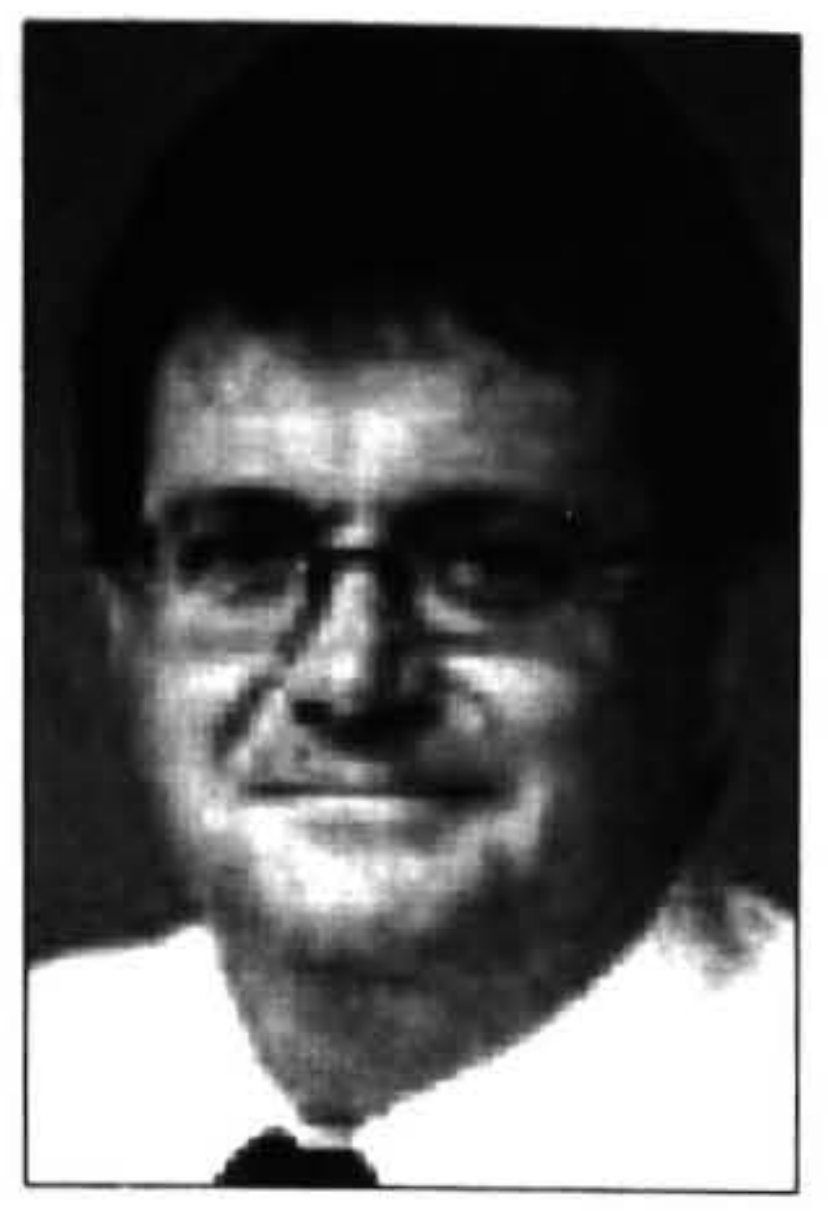

\title{
KNOWLEDGE CITIES
}

\author{
Stephen Bevan
}

The Work Foundation, London

\begin{abstract}
"Knowledge Cities" tries to disentangle the myths from the realities of the Knowledge Economy. It argues for a wider definition of the knowledge economy, bevond a simple definition based around ICT and biotechnology and including the creative industries, the public sector and manufacturing. With the right policies in place, there is no reason why the knowledge economy should be characterised by growing inequalit?:
\end{abstract}

In March 2000, European leaders committed the EU to become by 2010 the most dynamic and competitive knowledge-based economy in the world capable of sustainable economic growth with more and better jobs and greater social cohesion, and respect for the environment'. This has serious implications for the creation and exploitation of knowledge, and our capacity to harness knowledge as an economic asset.

The Knowledge Economy is seen by some as offering unlimited economic potential for increased productivity, leading to faster non-inflationary economic growth and ever-rising stock markets. Increasing the volume of knowledge intensive economic activity is essential if developed countries are to remain prosperous. This reflects a transition from an economy based on land, labour and capital to an economy where the source of comparative advantage is likely to be found in the production of information and knowledge. However the new economy enthusiasts were set-back by the dot.com crash: and more sceptical interpretation is that we are seeing more of the same, albeit operating on a bigger scale and at a faster pace. The truth lies somewhere between the two - a "soft discontinuity" rather than a sharp break from the past. Certainly the unprecedented combination of powerful ICT and highly educated workforces allows advanced economies to take advantage of these unique properties to develop knowledge based economic structures.

In the United Kingdom 48 per cent of jobs are in knowledge based industries, the Knowledge Economy's share of value added is 41 percent. The knowledge industries grew by 24 percent between 1995 and 2005 and Knowledge service exports trebled from $£ 27$ billion in 1995 to $£ 76$ billion in 2005 .

\section{The Role of 'Place'}

It is the link between the Knowledge Economy and place that motivates the concept of the 'Ideopolis'. The Ideopolis is the vision of a sustainable knowledge intensive city that drives growth in the wider city-region. It gives cities a framework for developing knowledge-intensive industries that will be economically successful and improve quality of life. Cities matter to businesses in the knowledge economy: they are the places that offer organisations access to highly skilled werkers, affluent consumers and the opportunity to innovate and exchange ideas. Ideopolises are characterised by: high levels of economic success, high levels of knowledge intensity based on The Work Foundation's definition of knowledge intensity, a diverse industry base including distinctive specialist niches, one or more universities that have a mutually beneficial relationship with the city, leading to industries built on research strengths, transfer of knowledge to businesses and the retention of graduates, strong communications infrastructure and good transport links within the city and to other cities, including by air, rail and road, a distinctive long-term 'knowledge city' offer to investors and individuals alike, created by public and private sector leaders, and strategies to ensure that all communities benefit from the economic success associated with knowledge.

Cities themselves are important because they contain $90 \%$ of the population, $91 \%$ of economic outputs and $89 \%$ of jobs; they are the spatial manifestation of economic and social 'hubs'. At the heart of Porter's 'Cluster' story for example lies the notion of the network - whether formal institutions for information exchange and technology transfer or informal arrangements between businesses. Cities provide a context for these processes. 
Figure 1: Knowledge Economy across the OECD in 2002 (Share of knowledge based industries in gross value added).

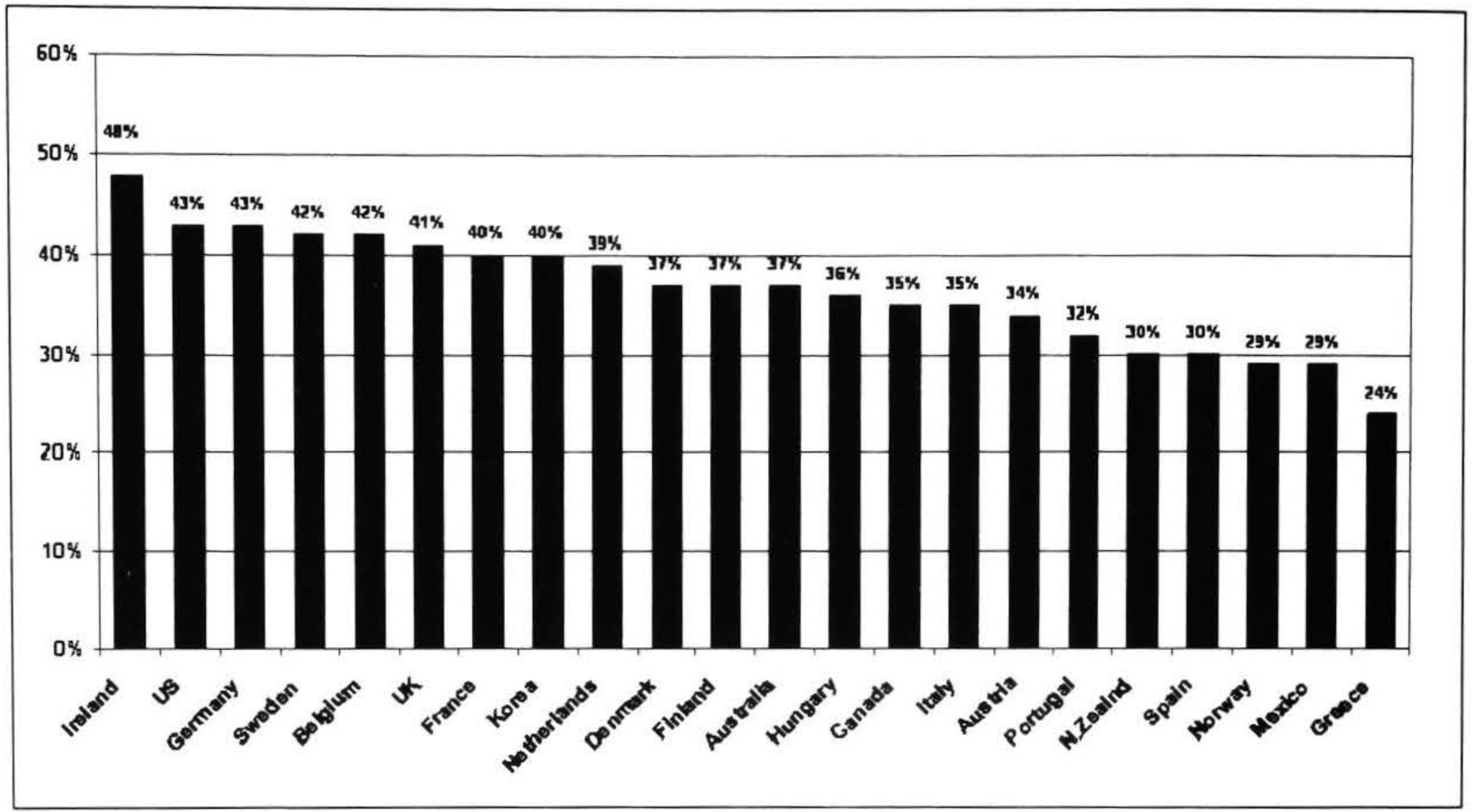

Vote: Current OECD definition of knowledge based industries; high to medium tech manufacturing: financial services: telecommunications; business services: education and health services.

Figure 2: Employment in knowledge based industries in 2005.

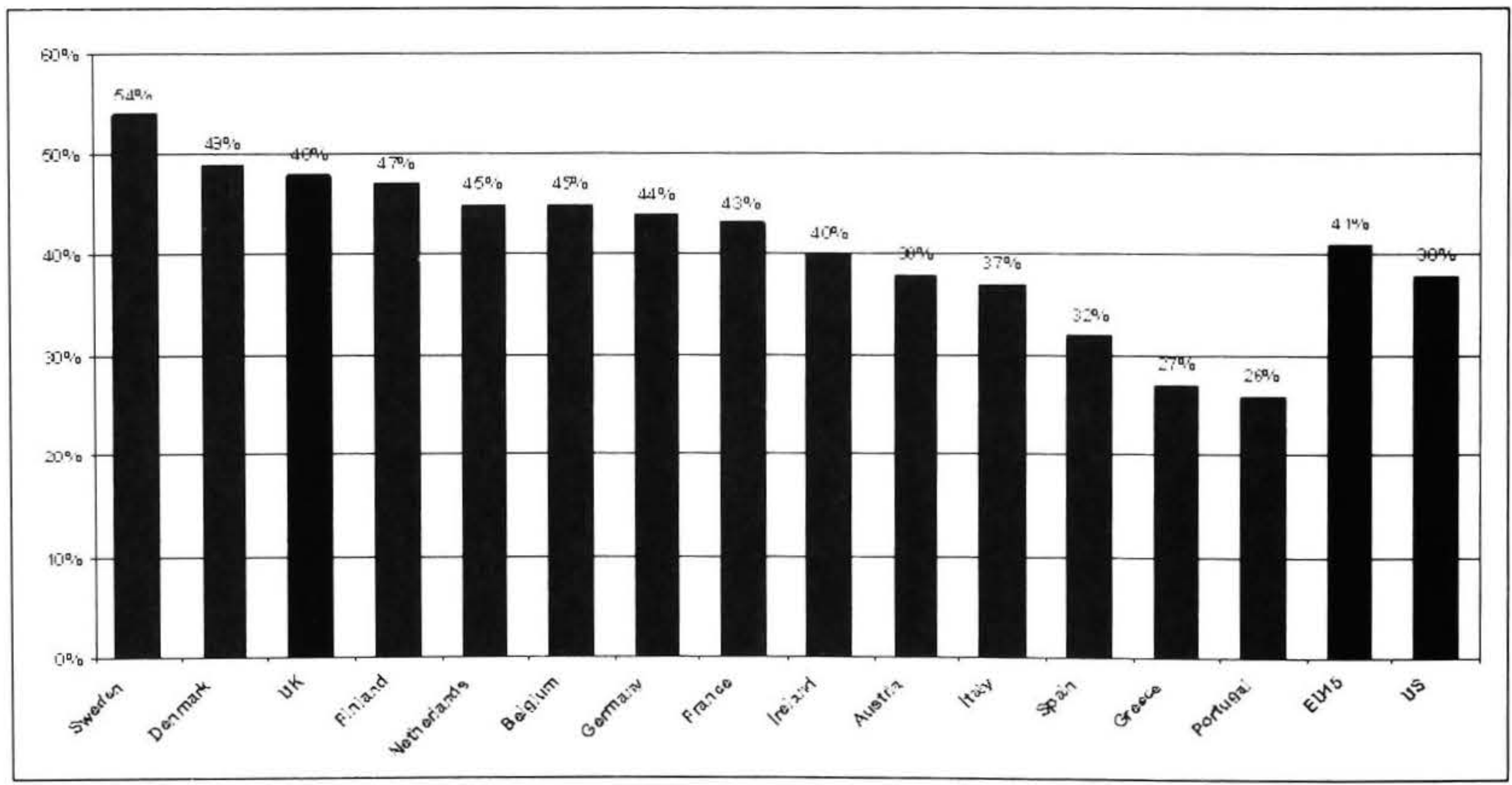

Vote: EU15 is share of total employment using Eurostat definitions (high to medium lech manulacturing, finance. husiness services, communications. health. education. cultural sersices, air and sea tratsel). (IS estimate is Worh Foundation estimate for share of emplovees derived from US Bureau of labor Statistics from similar industries. 
1. Creating the physical knowledge city: having the architecture and accommodation that knowledge intensive businesses and workers require.

2. Building on what's there: recognising the city's existing strengths and weaknesses and playing to these.

3. 'Diverse specialisation': having a diverse range of economic specialisms for which the city is known.

4. High skill organisations: organisations that rely on the 'high road' to productivity through high quality jobs and highly skilled people.

5. Vibrant education sector embedded in community and economy: one or more universities linking closely with the city and businesses, supported by good education institutions helping all individuals develop their skills.

6. Distinctive 'Knowledge City' offer: a distinctive offer for knowledge intensive businesses and workers who are considering investing, working and living in the city, supported by diverse cultural and leisure facilities.

7. Leveraging strong connectivity within and outside the city-region: good communications infrastructure combined with quick links both within the city and to other cities via air, rail and road.

8. Strong leadership around knowledge city vision, supported by networks and partnerships: civic or private sector leadership around the vision of a knowledge intensive city, based on strong networks across different industries.

9. Investing in communities: investing in strategies to ensure the benefits of knowledge intensity are experienced by the whole community.
The Ideopolis is a framework for growth within a region. Successful Ideopolises need to work with, and will drive economic growth in, other cities and areas within their region. Smaller cities can use the framework to drive growth and work with the core Ideopolis.

Secondary Ideopolis: Some cities are not the main drivers of growth in their city-region, and so cannot become Ideopolises. They can, however, use the Ideopolis framework to become Secondary Ideopolises' or 'Knowledge Cities' that link closely with an Ideopolis. This means that both the smaller and larger cities benefit from each other's different strengths, rather than setting up an unhelpful competition.

There is a 'tipping point' at which knowledge intensive businesses generate benefits for the city above and beyond any other sector: see Figure 3. This tipping point is increasing year by year. Based on the OECD definition of knowledge intensive businesses, 17 percent of a city's businesses need to be knowledge intensive for there to be a significant impact on economic success. Based on The Work Foundation definition, 25 percent of a city's businesses need to be knowledge intensive.

There is also a 'tipping point' at which knowledge intensive occupations make a real difference (Figure 4): cities where more than 14 percent of the working population are senior managers are more successful. Cities that have more than 19 percent of their workers with degree level qualifications see a significant increase in their economic success, and this increases further when more than 29 percent of the working population have a degree.

Figure 3: Tipping point - Knowledge-intensive businesses.

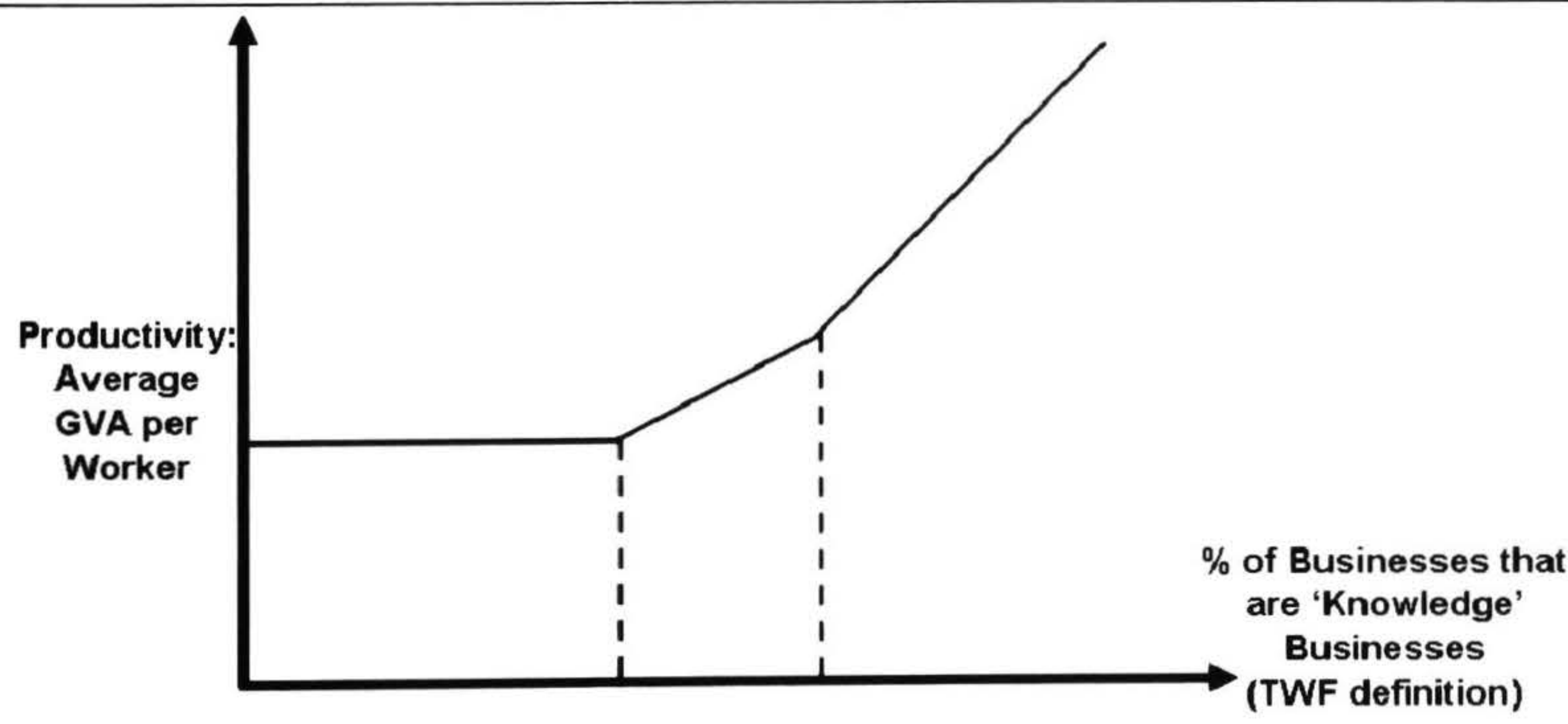

$\mathbf{2 5} \% \quad \mathbf{4 0} \%$ 


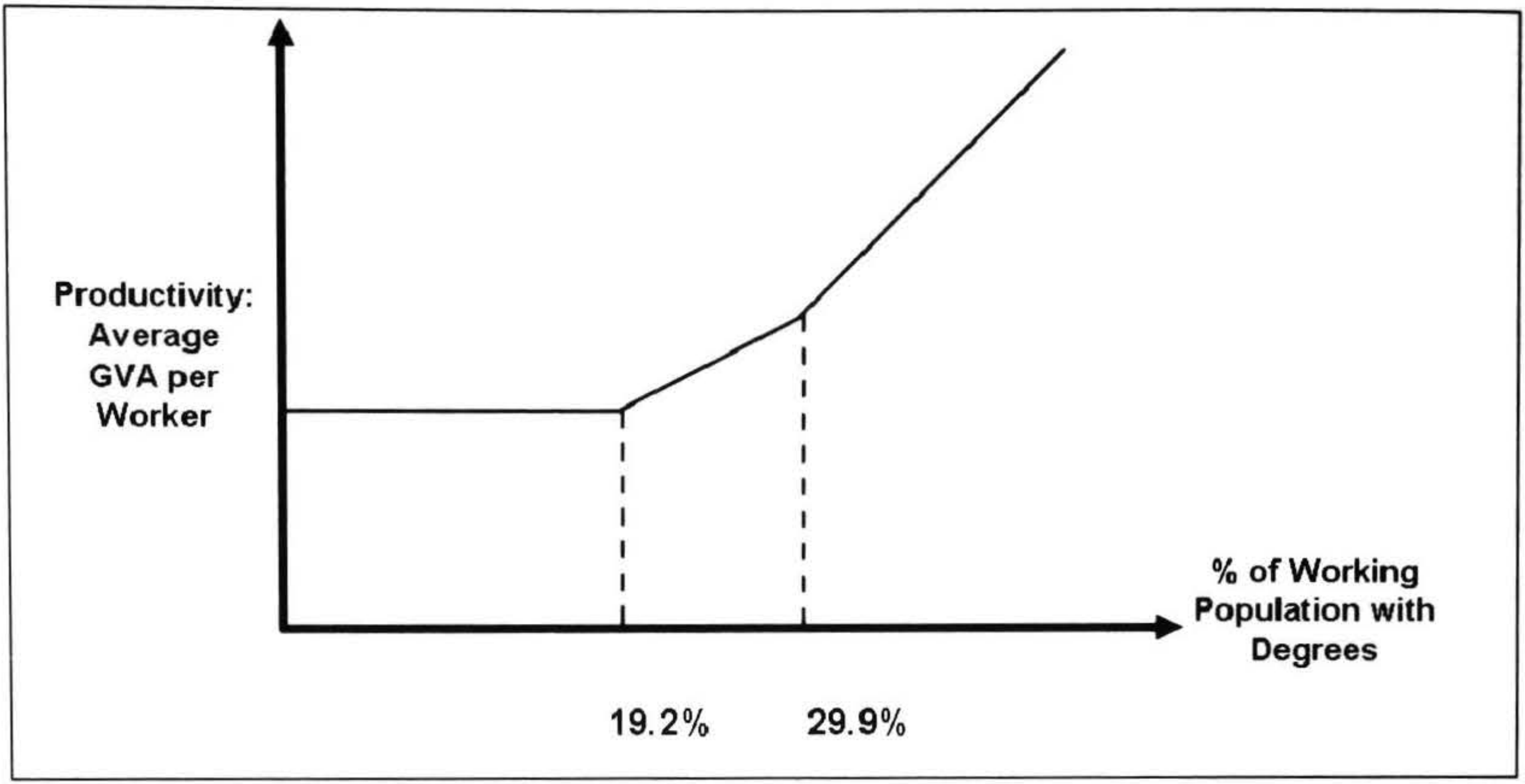

\section{Policy Implications}

The Knowledge Economy is not just about science and technology. It is about highly skilled individuals adding value to all industries and about knowledge intensive industries, which are more likely to employ highly skilled individuals. They require effective investment and the prioritisation of knowledgeintensity. They require planning powers over transport, skills and housing at city-region level. Universities need to be key partners in any development strategy. For Knowledge Cities to develop leadership must be empowered at regional/local level. In addition to their growth enhancing role Knowledge Cities can be a vehicle for social inclusion.

\section{Implications for Cities}

The concept of the Knowledge City has a number of implications for cities. The first of these is to conduct an 'audit' against the key drivers. The development of a Knowledge City requires focusing on strengths, investing in skills, concentrating on what makes the City distinctive, and maximising economic and social 'spillover' effects.

Those cities that want to become an Ideopolis should:

1. Conduct an 'Ideopolis audit': where is the eity now in terms of knowledge intensity, industry mix and demographics? What are the cities's main strengths and weaknesses?

2. Review whether the city could become an Ideopolis or a Secondary Ideopolis and plan accordingly.

3. Focus on building on the city's strengths, for example working with the university to identify research strengths, working with businesses to understand their needs in a location, or looking at the industrial legacy of a city and striving to make a particular sector more 'high value'.

4. Invest in local skills at all levels - tomorrow's knowledge workers already live in the city.

5. Concentrate on what makes the city distinctive as a way of attracting knowledge intensive businesses and investment.

6. Ensure that any strategy to increase knowledge intensity and economic success has a complementary strategy that allows benefits to be experienced by the whole community, rather than by-passing those in deprived communities or with lower skills. 